\title{
Dispatches from the editor: what do authors want from our military health journal?
}

In the current climate, our clear understanding of author requirements is essential for the continued survival of any journal. At the time of writing, there are approximately 62600 active scholarly peer reviewed English language journals in print and online. ${ }^{1}$ The number of peer reviewed journals published annually has been growing at a steady rate of about $3.5 \%$ for over three centuries thus the number of competitor journals to JRAMC has increased. ${ }^{2}$ Following the withdrawal from Iraq and Afghanistan, the number of submitted papers has inevitably decreased.

The importance of an impact factor, article visibility, journal indexing and ease of reader access are now the major factors determining the manner in which authors choose the journals they submit to. With the advent of vanity publishing and other pay to publish journal models soliciting potential authors, there is the potential to publish any paper - whatever its quality, should the author be willing to pay. How then do we ensure that authors continue to publish in the Journal of the Royal Army Medical Corps (JRAMC) considering the many options available?

\section{VISIBILITY}

One of the most prominent reasons for submitting to the JRAMC is due to its' broad readership base. The journal continues to be provided to all Royal Army Medical Corps (RAMC) officers through the RAMC Charity as part of the days giving scheme. In addition, many of the key UK military medical institutions as well as our international partners furnish their members with access. This provides a channel for junior military authors to publish a paper in the journal which is read by senior colleagues whose opinion they seek to influence. For example, the Surgeon General cannot hope to have time to personally read all of the UK military medical publications but we know

\footnotetext{
${ }^{1}$ Academic Department of Military Surgery and Trauma, Royal Centre for Defence Medicine, Birmingham, UK Division of Plastic, Maxillofacial, and Oral Surgery, Duke University Hospital, Durham, North Carolina, USA ${ }^{3}$ BMJ, London, UK

Correspondence to Johno Breeze, Academic Department of Military Surgery and Trauma, Royal Centre for Defence Medicine, Birmingham B15 2SQ, UK; editor.jramc@bmj.com
}

Table 1 The ten countries with the most submissions to the Journal of the Royal Army Medical Corps between 2013-2017

\begin{tabular}{lccccrr}
\hline Submitting Country & $\mathbf{2 0 1 3}$ & $\mathbf{2 0 1 4}$ & $\mathbf{2 0 1 5}$ & $\mathbf{2 0 1 6}$ & $\mathbf{2 0 1 7}$ & Total \\
\hline United Kingdom & 194 & 124 & 153 & 78 & 102 & 651 \\
United States & 13 & 8 & 9 & 13 & 5 & 48 \\
Turkey & 2 & 4 & 11 & 6 & 2 & 25 \\
China & 4 & 2 & 7 & 5 & 4 & 22 \\
France & 3 & 0 & 2 & 5 & 8 & 18 \\
Australia & 1 & 4 & 3 & 3 & 2 & 13 \\
Germany & 4 & 1 & 2 & 5 & 2 & 14 \\
Republic of Korea & 0 & 1 & 6 & 6 & 0 & 13 \\
Iran & 0 & 0 & 1 & 8 & 3 & 12 \\
Israel & 1 & 1 & 1 & 6 & 3 & 12 \\
\hline
\end{tabular}

that he reads the JRAMC. Most importantly, he continues to both support and publish in the journal.

Visibility has also increased internationally, reflected by the country of origin of authors submitting to us. This has been particularly noticeable since 2013, reflecting one of the main reasons for our partnership with BMJ (table 1). BMJ started out over 170 years ago as a medical journal. Now, as a values-driven company and global brand, it works with the vision of doing what it can to contribute to creating a 'healthier world'. BMJ publishes the newest academic research for healthcare professionals in over 60 medical and allied science journals, including some of the most influential specialty journals in their field.

The collaboration between RAMC and BMJ has provided a subscriber base and greater visibility of the journal than could be achieved alone.

In addition to the partnership, the other rationale for an increase in visibility is the introduction of an Impact Factor. The impact factor is calculated by dividing the number of citations in a given year by the total number of articles published in the two previous years. The number of citations an article and journal receives is widely used as a measure of quality, though increasingly criticised. ${ }^{3}$ However given the lack of an agreed suitable alternative in the Science, Technical and Medical (STM) community, authors are more likely to submit to journals with a higher impact factor and are often unlikely to submit to a journal that is yet to receive one.
There is little doubt from both readership surveys and discussion with authors that the current title of the journal limits our visibility. We have altered the journal strapline to reflect that we are an international health (and not just medical) journal, which goes some way to assuage the issue however, more must be done to alter the perception that JRAMC is only a journal for UK Army doctors.

\section{LIKELIHOOD OF ACCEPTANCE}

There is a considerable amount of work that goes into the preparation and submission of a medical manuscript and therefore authors deserve that their endeavours and perseverance will come to fruition in the publication of their article. Despite an overall drop in submissions, the acceptance rate for JRAMC has remained relatively unchanged. In 2013 we accepted 174/216 submissions compared with 96/136 in 2017 (Figure 1). This reflects a noticeable improvement in the quality of submissions, particularly the proportion of original research articles, which have increased from 52/216 in 2013 to $48 / 136$ in 2017 . The editorial team now regularly commission personal views and reviews from internationally respected authors, who in turn are encouraging their junior authors to submit to us.

One of the core values of the JRAMC has always been to support and encourage junior military authors. We always provide at least two constructive reviews and signpost junior authors of papers that are unsuitable for publication, to members of the editorial board who offer mentorship 


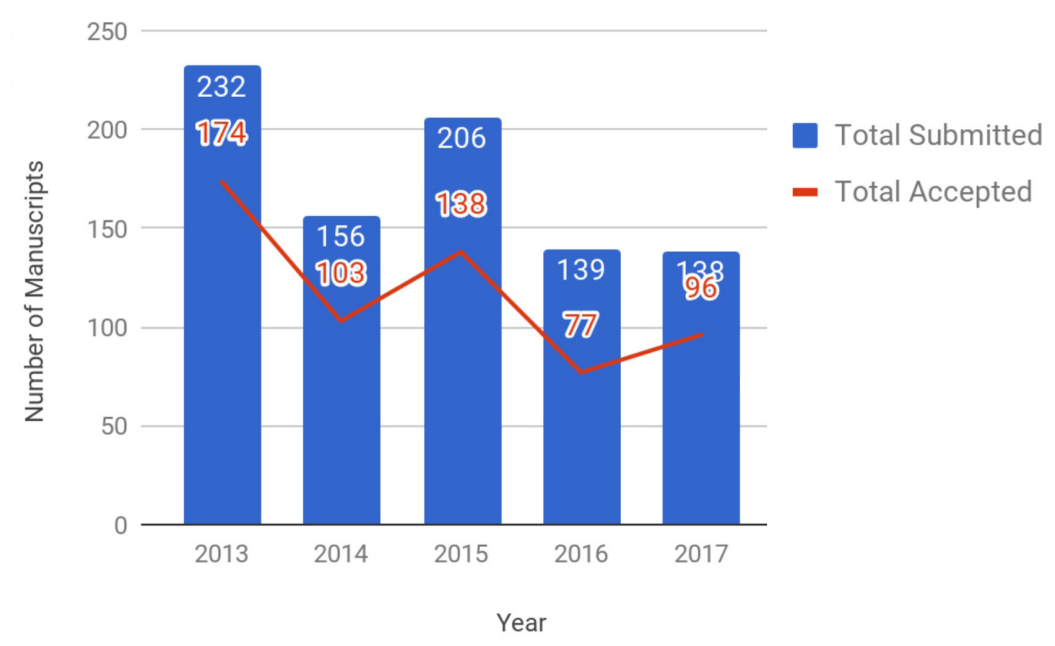

Figure 1 Submissions versus acceptances of all types of paper submitted to the Journal of the Royal Army Medical Corps between 2013-2017.

and work with them to ensure the article is suitable for resubmission.

Despite the large increase in international submissions, we see significantly lower acceptance rates from international authors in whom English is not their first language (table 2). This is a recognised difficulty across many journals and one which we seek to address. The BMJ Author Hub (http:// authors.bmj.com/) details information on a

Table 2 Percentage of papers accepted by country of author origin for all types of paper submitted to the Journal of the Royal Army Medical Corps between 2013-2017

\begin{tabular}{ll}
\hline Country & Percentage acceptance \\
\hline Canada & 100 \\
Netherlands & 100 \\
France & 79 \\
Germany & 79 \\
United Kingdom & 75 \\
United States & 72 \\
Australia & 50 \\
Israel & 50 \\
Turkey & 36 \\
China & 26 \\
\hline
\end{tabular}

Table 3 Times taken (in days) from initial submission to decision to accept or reject, publication online and in print for all types of paper submitted to the Journal of the Royal Army Medical Corps between January 2013- April 2018

\begin{tabular}{lllllll}
\hline $\begin{array}{l}\text { Mean times to key performance } \\
\text { indicators }\end{array}$ & $\mathbf{2 0 1 3}$ & $\mathbf{2 0 1 4}$ & $\mathbf{2 0 1 5}$ & $\mathbf{2 0 1 6}$ & $\mathbf{2 0 1 7}$ & $\mathbf{2 0 1 8}$ \\
\hline Time to First Decision (days) & 14 & 23 & 26 & 40 & 41 & 28 \\
Time to Acceptance (days) & 17 & 35 & 62 & 91 & 88 & 42 \\
$\begin{array}{l}\text { Time from Acceptance to Publication } \\
\text { Online (days) }\end{array}$ & 18 & 15 & 21 & 25 & 37 & 30 \\
$\begin{array}{l}\text { Time from Acceptance to Publication } \\
\text { in Print (months) }\end{array}$ & 3 & 6 & 5 & 4 & 9 & - \\
\hline
\end{tabular}
months for the article to be published. A large priority at $\mathrm{BMJ}$ has been to reduce these timings which are currently 30 days following acceptance to publication online (table 3).

Publication ahead of print (PAP) is of particular importance to the JRAMC due to our desire to group articles of certain themes together into special issues. This ensures that authors are not penalised by any potential delays to include them into these special issues.
The use of the Scholar One system since joining BMJ has streamlined the submission and review process. It provides the Associate Editors with clear information on how reviews are progressing, automating reminder emails and recommending potential reviews for those occasionally difficult to source reviewers. Authors are also kept up to date with the submission process via the editorial office and are able to log into their own 'author area' to check on the status at any time. However, many of our more senior authors will still look back fondly to the days when all a submission required was to print it out and post it to the EIC.

Previous readership surveys have shown that the field of military health has global relevance and a journal solely dedicated to the subject remains pertinent.

One of the great advantages of a smaller journal such as ours is that we continue to interact with our readership on a personal basis. Members of the editorial board regularly present a 'how to get published' session to potential junior authors on military courses and we try to maintain that link throughout their military, medical and publishing careers.

Many of the most senior members of the UK Defence Medical Services are proud to have had their first publication in our journal. However, in a military medical environment that continues to think of itself as fully integrated between services as well as healthcare disciplines, we are mindful that the journal must continue to evolve to meet the needs of our current and future authors.

\section{Correction notice Minor sentence change since publication to update Page 1 middle column, last paragraph "despite increasing" to "though increasingly".}

Funding The authors have not declared a specific grant for this research from any funding agency in the public, commercial or not-for-profit sectors.

Patient consent Not required.

Provenance and peer review Not commissioned; internally peer reviewed.

(C) Article author(s) (or their employer(s) unless otherwise stated in the text of the article) 2018. All rights reserved. No commercial use is permitted unless otherwise expressly granted.

To cite Breeze J, Langford CEJ. J R Army Med Corps 2018;164:65-66.

\section{J R Army Med Corps 2018;164:65-66. doi:10.1136/jramc-2018-000974}

\section{REFERENCES}

1 Ulrich's Web Directory. (accessed 19 Apr 2018) https:// ulrichsweb.serialssolutions.com

2 Mabe M. The growth and number of journals. Serials: The Journal for the Serials Community 2003;16:191-7.

3 Ware M, Mabe M. The STM Report: an overview of scientific and scholarly journal publishing. 4th Edn, 2015. (accessed 19 April 2018). 